\title{
Augmentation of Multifunctional Properties of Cellulosic Cotton Fabric Using Titanium Dioxide Nanoparticles
}

\author{
Mohamed Gouda ${ }^{1,2^{*}}$, Abdullah Ibrahim Aljaafari ${ }^{1}$ \\ ${ }^{1}$ Collage of Science, King Faisal University, Al-Hassah, Saudi Arabia \\ ${ }^{2}$ Textile Research Division, National Research Center, Cairo, Egypt \\ Email: *esmaeil2001@yahoo.com,mgoudaam@kfu.edu.sa
}

Received September 17, 2012; revised October 20, 2012; accepted November 3, 2012

\begin{abstract}
Titanium dioxide nanoparticle was synthesized by the reduction of titanium tetrachloride using borohydride, water as solvent, and polyvinyl-pyrrolidone as stabilizer. The average size of nano- $\mathrm{TiO}_{2}$ is estimated to be $5-10 \mathrm{~nm}$ using a transmission electron microscope (TEM); this was confirmed by X-ray diffraction and UV-Vis spectroscopy. Nano- $\mathrm{TiO}_{2}$ was impregnated into cotton fabric to impart multifunctional properties and this was confirmed by scanning electron microscope and scanning electron microscope coupled with high energy distribution X-Ray (SEM-EDX). The $\mathrm{TiO}_{2}$ nanoparticles loaded cotton fabrics showed excellent antibacterial activity against two representative bacteria, Staphylococcus aureus (Gram positive) 96.6\% and Klebsiella pneumonia (Gram negative) 95.2\%. Also, $\mathrm{TiO}_{2}$ nanoparticles enhanced the self-cleaning and the protection of cotton fabrics against UV radiation in comparison with the untreated cotton fabrics. The $\mathrm{TiO}_{2}$ nanoparticles were durable $\mathrm{in}$-situ cotton fabrics even after 20 laundering wash cycles.
\end{abstract}

Keywords: Cellulosic Cotton Fabric; $\mathrm{TiO}_{2}$-Nanoparticles; UV-Protection; Self-Cleaning; Antibacterial Properties

\section{Introduction}

Nanotechnology has gained increasing worldwide consideration because of offering huge benefits in a wide range of end utilities. The distinctive and new properties of nanomaterials have attracted not only scientists and researchers but also businesses community, due to their vast economical prospective. Utilization of nanotechnology in the textile industry has enormously increased due to its exclusive and important properties.

The first work on nanotechnology in textiles was carried out by Nano-Tex, a supplementary of the US-based Burlington Industries [1]. One of the common techniques used to apply nano-particles onto textiles is coating. The coating material applied to the surface of textiles is mostly composed of nano-particles, a surfactant, ingredients and a carrier medium [2]. Numerous methods can be used for coating onto fabrics, including spraying, transfer printing, washing, rinsing and padding. Of these methods, padding is the most generally used $[3,4]$. The nano-particles are attached to the fabrics by using a padder adjusted to an appropriate pressure and speed, followed by drying and curing. The properties imparted to textiles using nanotechnology include water repellence, soil resistance, wrinkle resistance, anti-bacterial, antistatic and UV-protection, flame retardation, enhancement

*Corresponding author. of dye ability and many others. Nanotechnology also improves the water-repellent property of the fabric by creating nano-whiskers, which are hydrocarbons and $1 / 1000$ of the size of a typical cotton fibre, that are added to the fabric to generate a peach fuzz effect without lowering the strength of cotton. The spaces between the whiskers on the fabric are smaller than the typical drop of water, but still larger than water molecules; water thus remains on the top of the whiskers and above the surface of the fabric $[1,5,6]$. However, liquid can still pass through the fabric, if pressure is applied. The application is permanent while maintaining breathability [1]. On the other hand, a hydrophobic property can be imparted to a cotton fabric by coating it with a thin nanoparticulate plasma film [7]. Furthermore, inorganic UV blockers are more preferable than the organic UV blockers as they are non-toxic and chemically stable under exposure to both high temperatures and UV. Inorganic UV blockers such as $\mathrm{TiO}_{2}, \mathrm{SiO}_{2}$ and $\mathrm{Al}_{2} \mathrm{O}_{3}$ [3,8-12] are frequently used. Various research activities for the UV-blocking treatment to fabric using nanotechnology have been conducted $[3,13]$. UV-blocking treatment for cotton fabrics was developed using the sol-gel method. A thin layer of titanium dioxide is formed on the surface of the treated cotton fabric which provides excellent UV-protection; the effect can be maintained after 50 home launderings [14]. In addition, the widespread applications of nano- $\mathrm{TiO}_{2}$ 
has two key advantages, (a) $\mathrm{TiO}_{2}$ is essential functional oxides, exhibiting excellent photo-catalytic activity [3, 8-10]. (b) $\mathrm{TiO}_{2}$ is bio-safe and biocompatible [15], and can be used for biomedical applications [16]. With these unique characteristics, $\mathrm{TiO}_{2}$ could be one of the most important nanomaterials in future applications. Titanium dioxide is a photocatalyst [10], during the reaction, the photocatalyst is able to decompose common organic matters in the air such as odour molecules, bacteria and viruses [17-25]. Titania $\left(\mathrm{TiO}_{2}\right)$ has three main polymorphs viz. anatase, rutile and brookite. Among these three kinds of crystal structure of $\mathrm{TiO}_{2}$, anatase $\mathrm{TiO}_{2}$ fine particles are the most active for photo-catalysis [26]. Titanium dioxide is widely used in different areas because of their unique photo-catalytic, electrical, electronic, optical, dermatological, and antibacterial properties [12,2733]. For these applications, the nanoparticles need to be dispersed homogeneously in the different matrices, and a number of new synthetic strategies have been developed in order to prevent particles agglomeration, and increase the stability of $\mathrm{TiO}_{2}$ nanoparticles dispersions [34-38].

The main objective of this paper is to prepare and characterize the titanium dioxide nanoparticles and its application on woven cotton fabrics to impart multifunctional properties.

\section{Experimental Methods}

\subsection{Materials}

Full bleached and scoured 100\% woven cotton fabric 130 $\mathrm{g} / \mathrm{m}^{2}$, sodium borohydride (Aldrich $\mathrm{CO}$ ), and polyvinylpyrrolidone $(\mathrm{PVP})(\mathrm{Mwt}=10.000)$ as stabilizer $($ Sigma CO), titanium tetrachloride (Aldrich $\mathrm{CO}$ ) and acrylic binder (Texacryl binder SLN). All laboratory chemicals used were of analytical grade.

\section{2. $\mathrm{TiO}_{2}$ Nanoparticles Preparation}

Titanium nanoparticle was synthesized by the reduction of titanium tetrachloride using borohydride, water as solvent, and polyvinyl-pyrrolidone as stabilizer according to the reported method [39] as follow; $50 \mathrm{ml}$ of $\mathrm{TiCl}_{4}$ was gradually added to the $200 \mathrm{ml}$ distilled water in an ice cool bath containing $4.5 \mathrm{wt} \%$ of polyvinylpyrrolidone. The beaker was removed from the ice bath and was kept in magnetic stirrer to make a homogeneous solution for $30 \mathrm{~min}$ at room temperature. $50 \mathrm{ml}$ of sodium borohydrate (5 gm in $100 \mathrm{ml}$ distilled water) was added to the beaker drop by drop touching the walls of the beaker under constant stirring for $1 \mathrm{~h}$. The solution turned into white colloid without any precipitation. After the complete reaction the solution was allowed to settle and was washed with distilled water for 5 times.

\subsection{Characterization of $\mathrm{TiO}_{2}$ Nanoparticles}

\subsubsection{Transmission Electron Microscopy (TEM)}

The shape and size of the particles were obtained through TEM, using a Philips EM201C apparatus operating at 80 $\mathrm{kV}$. The samples for TEM measurements were placed on carbon-coated copper grids. The samples for TEM measurements were prepared from much diluted dispersions of the particles in 2-propanol.

\subsubsection{X-Ray Diffraction (XRD)}

The crystalline phase on prepared nano- $\mathrm{TiO}_{2}$ was determined using XRD diffraction with $\mathrm{D} / \mathrm{max}-\mathrm{IV}$ dif- fractometer with $\mathrm{Cu} \mathrm{K} \alpha$ radiation $(\lambda=1.5418 \AA$ ). The sample was scanned from $10^{\circ}$ to $80^{\circ}(2 \theta)$. The crystallite domain size (D) was examined from the XRD peak based on the Scherrer equation [40].

\subsubsection{UV-Visible Spectroscopy}

UV-visible absorbance spectra of prepared $\mathrm{TiO}_{2}$ nanoparticles were obtained on UV-visible spectrophotometer using a UV-2200 (Shimadzu, Tokyo, Japan) in the range of $200-700 \mathrm{~nm}$.

\subsection{Cotton Fabric Sample Treatment}

Nano- $\mathrm{TiO}_{2}$ was applied to cotton fabric sample using pad-dry-cure method. Padding solution was prepared as following; $1 \mathrm{~g}$ of nanoparticles was sonicated for $30 \mathrm{~min}$ with $98 \mathrm{~g}$ water and $1 \mathrm{~g}$ of acrylic binder. The mixture was then stirred at $4000 \mathrm{rpm}$ for $1 \mathrm{~h}$. The cotton fabric sample was padded in the prepared solution and then passed through a padding mangle to remove the excess solution. A $100 \%$ wet pick-up was maintained for the fabric sample. Padded fabric sample was dried for 5 min at $80^{\circ} \mathrm{C}$ and then cured for $3 \mathrm{~min}$ at $140^{\circ} \mathrm{C}$. In order to evaluate the nanoparticles adhesion to the textile fibers, the treated fabrics were washed five times. For this purpose, laundry machine was used and the washing cycles were performed at $40^{\circ} \mathrm{C}$, using detergent without optical brighteners. Treated cotton fabric samples were characterized using scanning electron microscopy coupled with an energy dispersive $\mathrm{X}$-ray and evaluated for antibacterial activity, self-cleaning as well as UV-protection.

\section{Metal Content}

The metal content expressed as mmol/100 g fabric sample was quantitatively determined by using atomic absorption spectrophotometer, Varian SpectrAA (220) with graphite furnace accessory and equipped with deuterium as background corrector. The procedure is as follows: 0.5 $\mathrm{g}$ of dried fabric sample was dissolved in $10 \mathrm{~mL}$ of cold $72 \% \mathrm{H}_{2} \mathrm{SO}_{4}$. Taking $0.5 \mathrm{~mL}$ of this solution and diluting up to $25 \mathrm{~mL}$ using phosphate buffer solution (pH 7.6) before analysis. 


\subsection{Characterization of Treated Cotton Fabric Sample Using Scanning Electron Microscopy (SEM-EDX)}

High resolution scanning electron microscope (SEM) equipped with an energy dispersive spectroscopic (EDX) microanalysis (type JXA-840 an electron probe microanalyzer-JOEL), system was used to examine the surfaces of woven cotton samples at an acceleration voltage of $10 \mathrm{kV}$. The cotton fabric samples were coated with 10 $\mathrm{nm} \mathrm{Au/Pd}$ prior to SEM observation.

\subsection{Self-Cleaning Properties [41]}

The measured quantity of $3 \mathrm{~g}$ coffee powder was suspended in 100 distilled and heated for $5 \mathrm{~min}$ at $90^{\circ} \mathrm{C}$. Few drops of prepared coffee solution were introduced onto the cotton fabric sample and allowed to spread. One half of each stain on the fabric was exposed to sunlight for 12 - 48 hours while the other half was enclosed with a black paper to avoid its irradiation from sunlight. The exposed part of the stain was compared with that of the covered part for self-cleaning action. The self-cleaning action was quantified by comparing the K/S values of the exposed and the unexposed portion of the same stain. The values were calculated using UltraScan Color Measurement Spectrophotometer. The K/S value of the unexposed part of the stain was taken and the relative decrease percent in the $\mathrm{K} / \mathrm{S}$ value of the exposed part was calculated using the following relation:

$$
\mathrm{K} / \mathrm{S} \%=\frac{(\mathrm{K} / \mathrm{S}) \text { Unexposed }-(\mathrm{K} / \mathrm{S}) \text { Exposed }}{(\mathrm{K} / \mathrm{S}) \text { Unexposed }} \times 100
$$

Self-cleaning properties were determined according to the discoloration change of the treated and untreated fabrics

\subsection{UV Penetration and Protection Measurement}

The ability of a fabric to block UV light is given by the ultraviolet protection factor (UPF) values. A UV Penetration and Protection Measurement Systems Camspec M350 UV-visible spectrophotometer (SDL/ATLAS) was used to obtain the UPF value of the cotton fabric samples according to Australian-New Zealand Standard AS/NZS 4399:1996. A UPF value of 15 - 24 is classified as good protection, 25 - 39 as very good protection and above 40 as excellent protection against solar UV radiation.

\subsection{Antibacterial Activity Measurement}

Antibacterial tests for treated fabric samples were carried out with Staphylococcus aureus (ATCC No. 6538) (gram positive bacteria) and Klebsiella Pneumonia, (ATCC No. 4352) (gram negative bacteria). The Quantitative meas- urement was determined according to AATCC Test Method 100 - 2004. The reduction rate of bacteria by the treated fabrics is reported as $\mathrm{R}, \mathrm{R}=100(\mathrm{~B}-\mathrm{A}) / \mathrm{B}$. where $\mathrm{R}=\%$ reduction $\mathrm{A}=$ the number of bacteria recovered from the inoculated treated test sample swatches in the jar incubated over 24 hours and B = the number of bacteria recovered from the inoculated treated test example swatches in the jar immediately after inoculation (at " 0 " contact time).

\subsection{Washing Procedure}

To determine the durability of nano- $\mathrm{TiO}_{2}$ treated cotton fabrics, the fabric samples were washed 10 and 30 times at $40^{\circ} \mathrm{C} 30$ min with a Gyro wash laboratory type washing machine at the speed of $40 \mathrm{rpm}$. The treated fabric samples were subjected to laundering according to the EN ISO 20105-C01 standard test method, and AATCC standard ECE detergent without optical brighteners was used throughout the laundering cycles. A solution of detergent was prepared with a concentration of $5 \mathrm{~g} / \mathrm{L}$. Then, the samples were introduced into the laundry solution bath with a volume of $125 \mathrm{ml}$. When a cycle was finished, samples were washed twice with deionized water for 1 min.

\section{Results and Discussion}

\subsection{Characterization of $\mathrm{TiO}_{2}$ Nanoparticles Using X-Ray Diffraction (XRD)}

The formation of titanium dioxide nanoparticles synthesized was supported by X-ray diffraction measurements. Figure 1 shows that, XRD analysis showed seven distinct diffraction peaks at $25.3^{\circ}, 37.8^{\circ}, 47.9^{\circ}, 54.5^{\circ}, 62.8^{\circ}$, $69.5^{\circ}$ and $75.1^{\circ}$ which indexed the planes $101,004,200$, 105, 204, 116 and 215 respectively of the cubic face

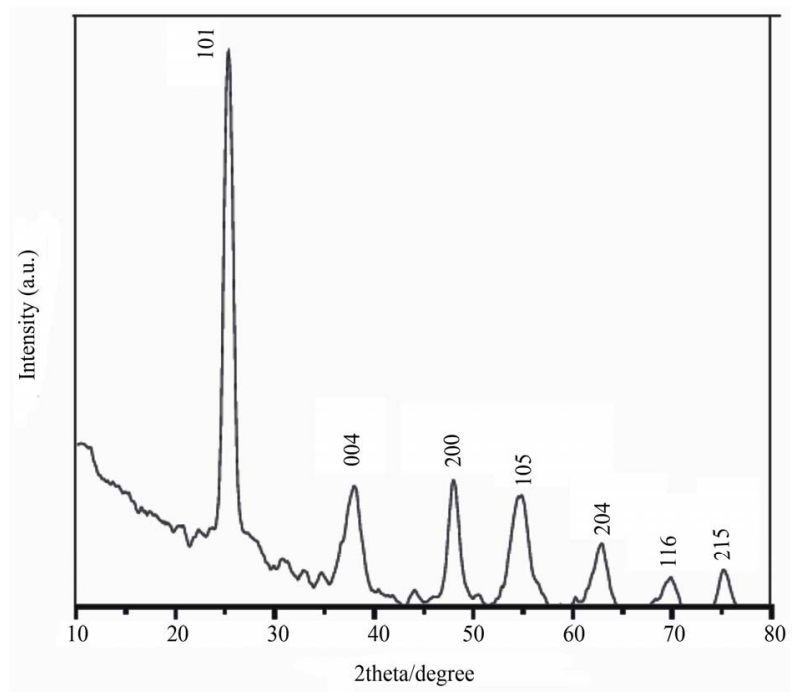

Figure 1. XRD pattern of $\mathrm{TiO}_{2}$ nanoparticles. 
centered titanium dioxide (JCPDS No. 21-1272). The sharp peaks and absence of unidentified peaks confirmed the crystallinity and higher purity of the prepared nanoparticles

\subsection{Characterization of $\mathrm{TiO}_{2}$ Nanoparticles Using TEM}

In order to investigate the size of the nanoparticles, the dispersion of the nanoparticles was sonicated at $30^{\circ} \mathrm{C}$ for 2 hours and the morphology of the dispersed samples was observed by TEM. As shown in Figure 2, the particle size of $\mathrm{TiO}_{2}$ was found to range between $5-10 \mathrm{~nm}$. TEM micrographs in Figure 2 shows that, the nanoparticles analysed are very stable and no aggregation could be observed.

\subsection{Characterization of Prepared Nanoparticles Loaded Fabric Sample Using UV-Visible Spectroscopy}

Figure 3 shows UV-Vis absorption spectra from $220 \mathrm{~nm}$ to $450 \mathrm{~nm}$ of $\mathrm{TiO}_{2}$ nanoparticles suspension solution. Strong absorption was observed at the wavelengths lower than $270 \mathrm{~nm}$. This fact indicates that the $\mathrm{TiO}_{2}$ nanoparticles suspension possesses a high ability to absorb ultraviolet light.

\subsection{Characterization of Nano- $\mathrm{TiO}_{2}$-Loaded Cotton Fabric Sample by Scanning Electron Microscopy (SEM)}

The surfaces of the treated fabrics were observed by SEM microscopy. In Figure 4, SEM micrograph shows the nanoscaled $\mathrm{TiO}_{2}$ particles on cotton fabric samples ((a), before treatment) and ((b), after treatment) samples. The nanoparticles are well dispersed on the surface of the cotton fabric samples.

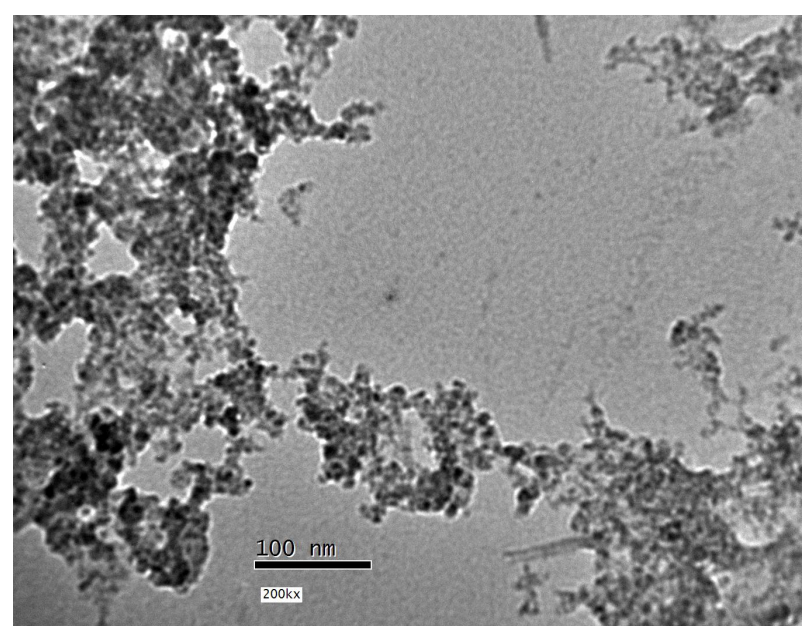

Figure 2. TEM image $\mathrm{TiO}_{2}$ nanoparticles prepared in presence of $4.5 \mathrm{wt} \% \mathrm{PVP}$.

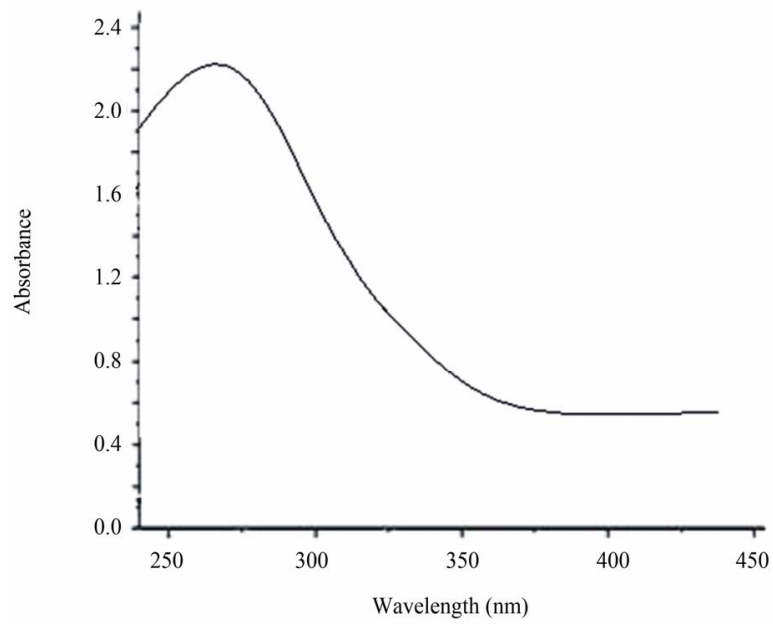

Figure 3. UV-Vis absorption spectra of $\mathrm{TiO}_{2}$ nanoparticles.

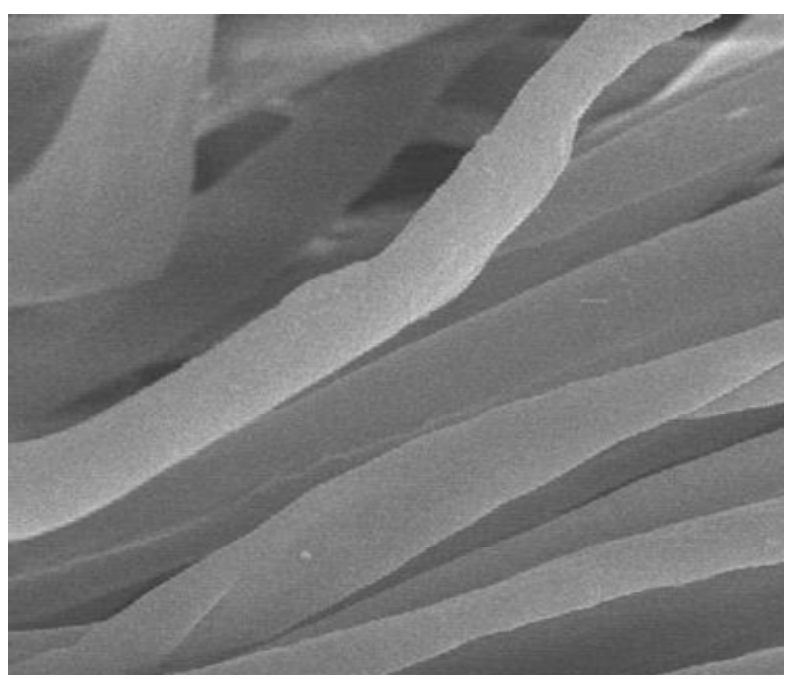

(a)

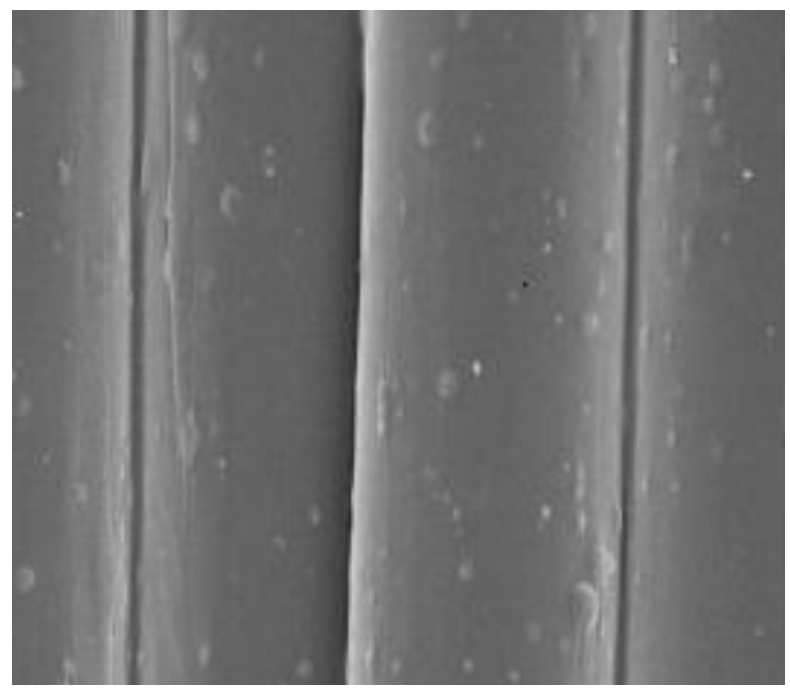

(b)

Figure 4. SEM images of $\mathrm{TiO}_{2}$ nanoparticles on: (a) before treatment; (b) after treatment. 


\subsection{Characterization of Nano- $\mathrm{TiO}_{2}$ Loaded Cotton Fabric Sample by EDX}

The chemical composition of one nanoparticle was analyzed by EDX point analysis. The resulting spectrum, Figure 5, indicates the presence of $\mathrm{Ti}$ as main element. This analysis is important because it indicates that the nanoparticles are essentially $\mathrm{TiO}_{2}$ with no indication of contamination at all.

\subsection{Self-Cleaning Action of $\mathrm{Nano}^{-\mathrm{TiO}_{2}}$ Loaded Cotton Fabric Sample}

The results are given as the increasing in the rate of reduction of stain expressed as a percentage decrease in $\mathrm{K} / \mathrm{S}$ values of coffee stained cotton fabric samples loaded with $\mathrm{TiO}_{2}$ nanoparticles. It can be observed from Table 1 that, the untreated cotton fabric sample has got the lowest rate of reduction regarding exposure time. However the rate of reduction of stain expressed as decreasing in the $\mathrm{K} / \mathrm{S} \%$ increases significantly in the presence of nano$\mathrm{TiO}_{2}$. It can be concluded from the above observations that the improvement in stain release is because of the nano-topological application of $\mathrm{TiO}_{2}$ and with the smaller size of the nanoparticles, there is an improvement of the self-cleaning function of the nano titanium dioxide, and this is attributed to the photocatalytic properties of nano- $\mathrm{TiO}_{2}$. In these reactions, the organic compounds such as dirt, pollutants, and microorganisms. Since the nano-titanium dioxide only acts as a catalyst to the reactions, it is never used up. This allows the nano- $\mathrm{TiO}_{2}$ to continue breaking down stains over and over [42].

\subsection{UV-Protection of Nano- $\mathrm{TiO}_{2}$ Loaded Cotton Fabric Sample}

Figure 6 illustrates the change in UPF values of treated fabric samples. It is obvious that, increasing the $\mathrm{TiO}_{2}-$ content results in an amazing enhancement in the UVprotection which mainly attributed to the synergistic effect of $\mathrm{TiO}_{2}$ nanoparticles on the extent of UV-absorption and minimizing the degree of UV-transmittance, i.e. remarkable UV-protection property of the treated substrate.

\subsection{Antibacterial Activities of $\mathrm{Nano}-\mathrm{TiO}_{2}$ Loaded Cotton Fabric Sample}

$\mathrm{TiO}_{2}$ is preferable to other inorganic forms of titanium because of its higher efficiency in preventing infection. It

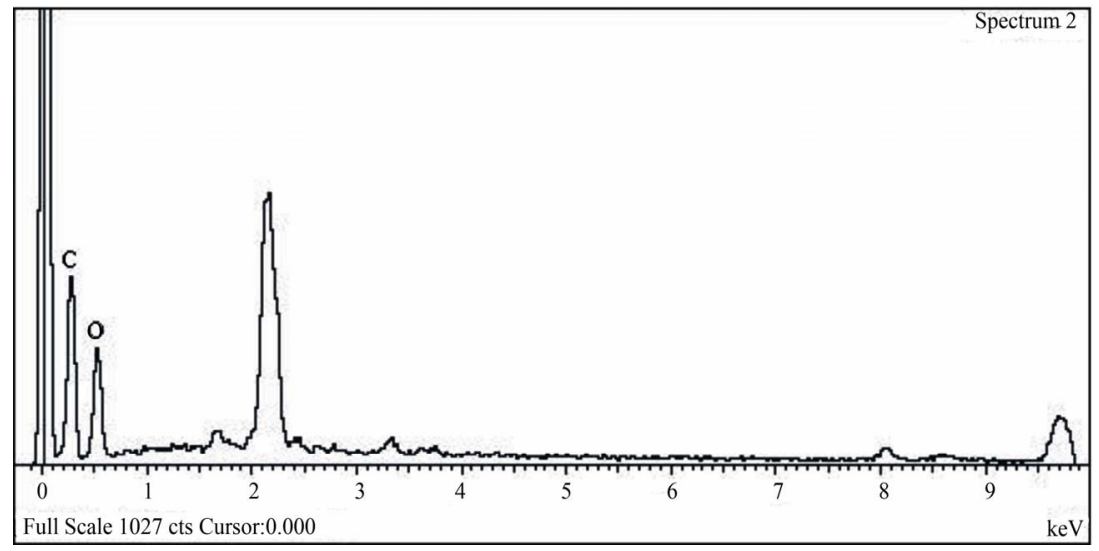

(a)

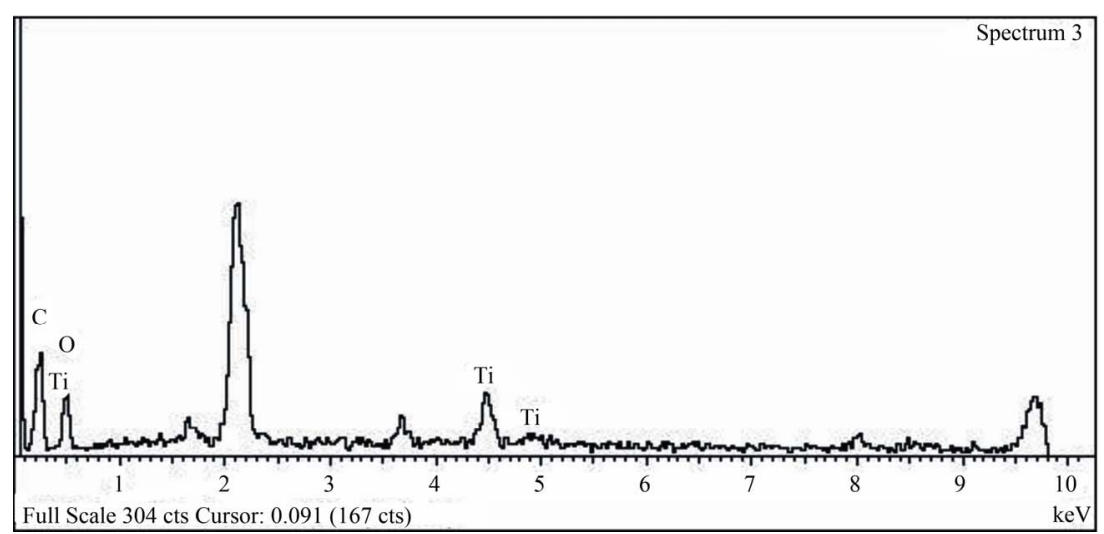

(b)

Figure 5. EDX spectrum of (a) untreated cotton fabric and (b) treated cotton fabric with $\mathrm{TiO}_{2}$ nanoparticles. 


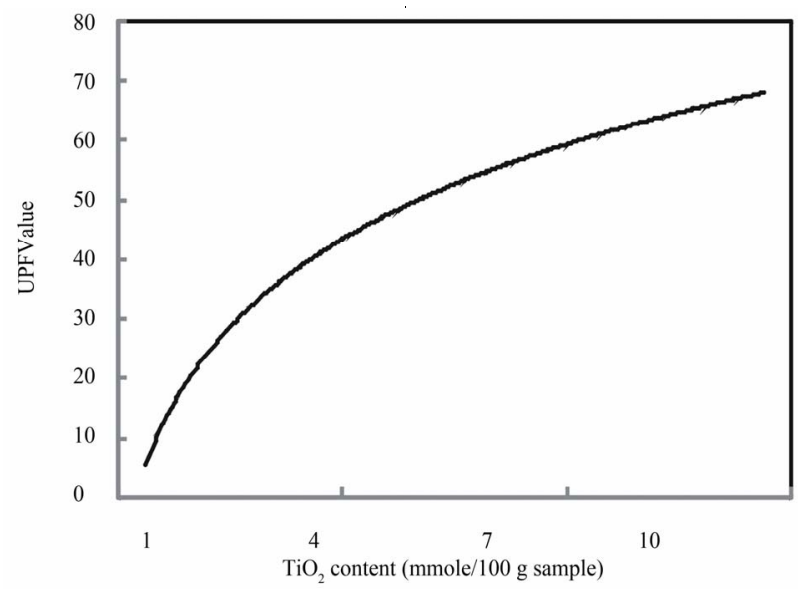

Figure 6. Effect of nano- $\mathrm{TiO}_{2}$ content on the UPF values.

Table 1. Percent decrease in $\mathrm{K} / \mathrm{S}$ values of stained cotton fabric sample loaded with $\mathrm{TiO}_{2}$ nanoparticles.

\begin{tabular}{|c|c|c|}
\hline \multirow{2}{*}{ Fabric samples } & \multicolumn{2}{|c|}{ \% Decrease in K/S values } \\
\hline & $\begin{array}{l}\text { Exposure } \\
\text { time (hr) }\end{array}$ & $\begin{array}{c}\text { Decrease of } \\
\text { K/S \% }\end{array}$ \\
\hline \multirow{4}{*}{$\begin{array}{l}\text { Untreated cotton } \\
\text { fabric samples }\end{array}$} & 0 & 0 \\
\hline & 6 & 6 \\
\hline & 12 & 5 \\
\hline & 24 & 4 \\
\hline \multirow{4}{*}{$\begin{array}{l}\text { Treated cotton fabric } \\
\text { sample with } \\
\text { nano- } \mathrm{TiO}_{2}\end{array}$} & 0 & 40 \\
\hline & 6 & 70 \\
\hline & 12 & 80 \\
\hline & 24 & 84 \\
\hline
\end{tabular}

is clear from Table 2 that, the untreated cotton fabric sample has no reduction in the bacterial count against both Staphylococcus aureus and Klebsiella pneumonia while in the nano- $\mathrm{TiO}_{2}$ treated cotton fabric sample has exhibited better reduction of bacterial count $\%$ and this is because nano- $\mathrm{TiO}_{2}$ has photocatalytic effect and when exposed to light, photons with energy equal to or greater than the band gap of the titanium dioxide excite electrons up to the conduction band. The excited electrons within the crystal structure react with oxygen atoms in the air, creating free-radical oxygen. These oxygen atoms are powerful oxidizing agents, which can break down the cell wall of microorganisms through oxidation-reduction reactions [42].

\subsection{Durability of Nano- $\mathrm{TiO}_{2}$ Loaded Cotton Fabric Sample}

To examine the durability to wash, and as the textile items are washed many times during the life, the treated
Table 2. Reduction of bacterial count $\%$ of nano- $\mathrm{TiO}_{2}$ treated cotton fabric samples against Staphylococcus aureus and Klebsiella pneumoniae.

\begin{tabular}{ccc}
\hline \multirow{2}{*}{ Samples } & \multicolumn{2}{c}{ Reduction of bacterial count \% } \\
\cline { 2 - 3 } & $\begin{array}{c}\text { Staphylococcus } \\
\text { aureus }\end{array}$ & $\begin{array}{c}\text { Klebsiella } \\
\text { pneumoniae }\end{array}$ \\
\hline $\begin{array}{c}\text { Untreated cotton } \\
\text { fabric }\end{array}$ & No reduction & No reduction \\
$\begin{array}{c}\text { Treated cotton } \\
\text { fabric with } \\
\text { nano- } \mathrm{TiO}_{2}\end{array}$ & 96.6 & \\
\hline
\end{tabular}

Table 3. Antibacterial activity and UPF of treated cotton fabric with nano- $\mathrm{TiO}_{2}$ using different laundering cycles.

\begin{tabular}{cccc}
\hline & & \multicolumn{2}{c}{ Antibacterial activity } \\
\cline { 3 - 4 } $\begin{array}{c}\text { Washing } \\
\text { cycles }\end{array}$ & UPF & $\begin{array}{c}\text { Staphylococcus } \\
\text { aureus }\end{array}$ & $\begin{array}{c}\text { Klebsiella } \\
\text { pneumoniae }\end{array}$ \\
\cline { 3 - 4 } & 50 & RBC\% & RBC\% \\
\hline 10 & 45 & 96.6 & 95.2 \\
20 & 40 & 95.8 & 93.5 \\
\hline
\end{tabular}

fabric samples were subjected to, 1,10 , and 20 wash cycles in home laundering machine and subjected to UPF and antibacterial activity tests according to the above mentioned testing methods. From Table 3 the data shows that, increasing the wash cycle from 1 to 20 results in a decrease in UPF value as well as a decrease in RBC values. RBC\% values of the Klebsiella pneumonia, was less than that of the Staphylococcus aureus, most probably due to the multilayered structure of the Klebsiella pneumonia cell wall, compared with a single layer of the Staphylococcus aureus cell wall, which needs more concentration of nanoparticles active ingredients for killing. On the other hand, very good UV-protection capacity as well as the maintained excellent antibacterial ability even after repeated 20 washing cycles were observed indicating that the multifunctionality of the obtained fabrics using the new treating process, i.e. treatment to get insitu deposition of the nano- $\mathrm{TiO}_{2}$ is still durable.

\section{Conclusion}

Nano- $\mathrm{TiO}_{2}$ was synthesized via reduction of titanium tetrachloride using sodium borohydride in the presence of polyvinylpyrrolidone as stabilizing agent. Synthesized nano- $\mathrm{TiO}_{2}$ was characterized using XRD, TEM, as well as UV-visible spectrophotometry. Prepared $\mathrm{Nano}-\mathrm{TiO}_{2}$ was applied to cotton fabric sample by pad-dry-cure method using acrylic binder to impart self-cleaning, antibacterial as well as UV-protection functions. The fabric 
samples treated with the $\mathrm{TiO}_{2}$ nanoparticles exhibit attractive UV-protection and self-cleaning properties as well as killing microorganisms, which could render them useful in applications such as multifunctional textiles. Nano- $\mathrm{TiO}_{2}$ loaded cotton fabric sample was durable to wash and it was very good UV-protection capacity as well as the maintained excellent antibacterial activity even after repeated 20 washing cycles. The durability after washing cycles validates the feasibility of using deposition process to develop potentially multifunctional textiles.

\section{REFERENCES}

[1] E. Russell, "Nanotechnologies and the Shrinking World of Textiles," Textile Horizons, Vol. 9, No. 10, 2002, pp. 7-9.

[2] R. D. Cramer, E. A. Ponomarenko, St. Laurent and J. C. T. R. Burckett, "Method of Applying Nanoparticles," US Patent No. 6645569, 2003.

[3] J. H. Xin, W. A. Daoud and Y. Y. Kong, "A New Approach to UV-Blocking Treatment for Cotton Fabrics," Textile Research Journal, Vol. 74, No. 2, 2004, pp. 97100. doi:10.1177/004051750407400202

[4] S. Y. Yeo, H. J. Lee and S. H. Jeong, "Preparation of Nanocomposite Fibers for Permanent Antibacterial Effect,” Journal of Materials Science, Vol. 38, No. 10, 2003, pp. 2143-2147. doi:10.1023/A:1023767828656

[5] D. Draper, "Very Little to It," World Sports Activewear, Vol. 19, No. 1, 2003, pp. 16-17.

[6] S. S. Kathiervelu, "Applications of Nanotechnology in Fibre Finishing,” Synthetic Fibres, Vol. 32, No. 1, 2003, pp. 20-22.

[7] J. Zhang, P. France, A. Radomyselskiy, S. Datta, J.-G. Zhao, and W. van Ooij, "Hydrophobic Cotton Fabric Coated by a Thin Nanoparticulate Plasma Film,” Journal of Applied Polymer Science, Vol. 88, No. 6, 2003, pp. 1473-1481. doi:10.1002/app.11831

[8] N. Burniston, C. Bygott and J. Stratton, "Nano Technology Meets Titanium Dioxide,” Surface Coatings International Part A, Vol. 88, No. A2, 2004, pp. 179-814.

[9] Sherman and Jonathan, "Nanoparticulate Titanium Dioxide Coatings, and Processes for the Production and Use thereof,” US Patent No. 736738, 2003.

[10] H. Y. Yang, S. K. Zhu and N. Pan, "Studying the Mechanisms of Titanium Dioxide as Ultraviolet-Blocking Additive for Films and Fabrics by an Improved Scheme," Journal of Applied Polymer Science, Vol. 92, No. 5, 2003, pp. 3201-3210. doi:10.1002/app.20327

[11] M. Saito, “Antibacterial, Deodorizing, and UV Absorbing Materials Obtained with Zinc Oxide (ZnO) Coated Fabrics,” Journal of Coated Fabrics, Vol. 23, No. 2, 1993, pp. 150-164.

[12] M. N. Xiong, G. X. Gu, B. You and L. M. Wu, "Preparation and Characterization of Poly (Styrene Butylacrylate) Latex/Nano-ZnO Nanocomposites,” Journal of Applied Polymer Science, Vol. 90, No. 7, 2003, pp. 1923-1931.

\section{doi:10.1002/app.12869}

[13] W. A. Daoud and J. H. Xin, "Nucleation and Growth of Anatase Crystallites on Cotton Fabrics at Low Temperatures," Journal of the American Ceramic Society, Vol. 87, No. 5, 2004, pp. 953-955. doi:10.1111/j.1551-2916.2004.00953.x

[14] R. H. Wang, J. H. Xin, X. M. Tao and W. A. Daoud, "ZnO Nanorods Grown on Cotton Fabrics at Low Temperature," Chemical Physics Letters, Vol. 398, No. 1-3, 2004, pp. 250-255. doi:10.1016/j.cplett.2004.09.077

[15] E. L. Romero, "The Involvement of Nano-Drug Delivery in Biosafety Issues,” Biosafety, Vol. 1, No. 2, 2012, pp. 1-5

[16] L. Hua and Q. G. Li, "Development of Nano-TiO2 Coating on Titanium Alloy Substrate for Biomedical Applications," Advanced Materials Research, Vol. 528, No. 1, 2012, pp. 27-30

[17] W. A. Daoud and J. H. Xin, "Low Temperature Sol-Gel Processed Photocatalytic Titania Coating," Journal of Sol-Gel Science and Technology, Vol. 29, No. 1, 2004, pp. 25-29. doi:10.1023/B:JSST.0000016134.19752.b4

[18] A. Bozzi, T. Yuranova and J. Kiwi, "Self-Cleaning of Wool-Polyamide and Polyester Textiles by TiO2-Rutile Modification under Daylight Irradiation at Ambient Temperature," Journal of Photochemistry and Photobiology A: Chemistry, Vol. 172, No. 1, 2005, pp. 27-34. doi:10.1016/j.jphotochem.2004.11.010

[19] S. Y. Cui, Y. D. Zu, H. Q. Hui and J. Y. Zhang, "Study on Anti-Bacteria Properties of Nano-Ceramics," Journal of Hebei University of Science and Technology, Vol. 24, No. 1, 2003, pp. 19-22.

[20] R. Q. Chen, "Nanometer Materials and Health-Care Textiles,” Dyestuff Industry, Vol. 39, No. 2, 2002, pp. 24-28.

[21] R. H. Wang, J. H. Xin, Y. Yang, H. F. Liu, L. M., Xu, and J. H. Hu, "The Characteristics and Photocatalytic Activities of Silver Doped ZnO Nanocrystallites,” Vol. 227, No. 1-4, 2004, pp. 312-317.

[22] Y. Yasuhide, N. Masahiko and S. Kenji, "Composite Material Carrying Zinc Oxide Fine Particles Adhered Thereto and Method for Preparing Same,” EP Patent No. 0791681, 1997.

[23] N. Vigneshwaran, S. Kumar, A. A. Kathe, P. V. Varadarajan and V. Prasad, "Functional Finishing of Cotton Fabrics Using Zinc Oxide-Soluble Starch Nanocomposites," Nanotechnology, Vol. 17, No. 20, 2006, pp. 5087-5095. doi:10.1088/0957-4484/17/20/008

[24] Y. W. H. Wong, C. W. M. Yuen, M. Y. S. Leung, S. K. A. $\mathrm{Ku}$ and H. L. I., Lam, "Selected Applications of Nanotechnology in Textiles,” Autex Research Journal, Vol. 6, No. 1, 2006, pp. 1-10.

[25] A. Yadav, V. Prasad, A. A. Kathe, S. Raj, D. Yadav, C. Sundaramoorthy and N. Vigneshwaran, "Functional Finishing in Cotton Fabrics Using Zinc Oxide Nanoparticles,” Bulletin of Material Science, Vol. 29, No. 6, 2006, pp. 641-645. doi:10.1007/s12034-006-0017-y

[26] S. Kathirvelu, L. D’Souza and B. Dhurai, "Synthesis and Characterization of Titanium Dioxide Nanoparticles and Their Applications to Textiles for Microbe Resistance,” 
Indian Journal of Science and Technology, Vol. 1 No. 7, 2008, pp. 1-12

[27] M. Turkoglu, S. Yener, "Design and in Vivo Evaluation of Ultrafine Inorganic Oxide Containing Sun-Screen Formulations," International Journal of Cosmetic Science, Vol. 19, No. 4, 1997, pp. 193-201. doi:10.1111/j.1467-2494.1997.tb00182.x

[28] Z. W. Pan, Z. R. Dai and Z. L. Wang, "Nanobelts of Semiconducting Oxides," Science, Vol. 291, No. 5510, 2001, pp. 1947-1949. doi:10.1126/science.1058120

[29] M. S. Arnold, P. Avouris, Z. W. Pan and Z. L. Wang, "Field-Effect Transistors Based on Single Semiconducting Oxide Nanobelts,” The Journal of Physical Chemistry B, Vol. 107, No. 3, 2003, pp. 659-663. doi:10.1021/jp0271054

[30] J. Sawai, “Quantitative Evaluation of Antibacterial Activities of Metallic Oxide Powders ( $\mathrm{ZnO}, \mathrm{MgO}$ and $\mathrm{CaO}$ ) by Conductimetric Assay," Journal of Microbiological Methods, Vol. 54, No. 2, 2003, pp. 177-182. doi:10.1016/S0167-7012(03)00037-X

[31] M. A. Behnajady, N. Modirshahla and R. Hamzavi, "Kinetic Study on Photo-Catalytic Degradation of C. I. Acid Yellow 23 by ZnO Photocatalyst,” Journal of Hazardous Materials, Vol. 133, No. 1-3, 2006, pp. 226-232. doi:10.1016/j.jhazmat.2005.10.022

[32] Y. Q. Li, S. Y. Fu and Y. M. Mai, "Preparation and Characterization of Transparent ZnO/Epoxy nanocompo- sites with High-UV Shielding Efficiency,” Polymer, Vol. 47, No. 6, 2006, pp. 2127-2132. doi:10.1016/j.polymer.2006.01.071

[33] E. Tang, G. Cheng, X. Pang, X. Ma and F. Xing, "Synthesis of Nano-ZnO/Poly (Methylmethacrylate) Composite Microsphere through Emulsion Polymerization and Its UV Shielding Property,” Colloid \& Polymer Science, Vol. 284, No. 4, 2006, pp. 422-428. doi:10.1007/s00396-005-1389-z

[34] L. Guo, S. H. Yang, C. L. Yang, P. Yu, J. N. Wang, W. K. Ge and G. K. L. Wong, "Synthesis and Characterization of Poly(Vinylpyrrolidone)-Modified Zinc Oxide Nanoparticles,” Chemistry of Materials, Vol. 12, No. 8, 2000, pp. 2268-2274. doi:10.1021/cm9907817

[35] Y. J. Kwon, K. H. Kim, C. S. Lim and K. B. Shim, "Characterization of ZnO Nanopowders Synthesized by the Polymerized Complex Method via an Organochemical Route,” Journal of Ceramic Processing Research, Vol. 3, No. 3, 2002, pp. 146-149.

[36] Y. Wang, C. Ma, X. Sun and H. Li, "Preparation of Nanocrystalline Metal Oxide Powders with the Surfactant Mediated Method," Inorganic Chemistry Communications, Vol. 5, No. 10, 2002, pp. 751-755. doi:10.1016/S1387-7003(02)00546-4

[37] S. C. Liufu, H. Xiao and Y. Li, "Investigation of PEG Adsorption on the Surface of Zinc Oxide Nanoparticles," Powder Technology, Vol. 145, No. 1, 2004, pp. 20-24. doi:10.1016/j.powtec.2004.05.007

[38] E. Tang, G. X. Cheng and X. Ma, "Preparation of NanoZnO/PMMA Composite Particles via Grafting of the Copolymer onto the Surface of Zinc Oxide Nanoparticles," Powder Technology, Vol. 161, No. 3, 2006, pp. 209-214. doi:10.1016/j.powtec.2005.10.007

[39] V. Parthasarathi and Thilagavathi, "Synthesis and Characterization and Their Application to Textile for Microbe Resistance," Journal of Textile Apparel Technology and Management, Vol. 6, No. 2, 2009, pp. 1-8.

[40] B. D. Cullity, "Elements of X-Ray Diffraction,” AddisonWesley Publishing Co., Inc., Boston, 1978.

[41] A. Aksit, N. Onar, M. F. Ebeoglugil, I. Kayatekin and E. Celik, "Proceedings of the 7th World Textile Conference AUTEX,” Tampere University of Technology Publications, Tampere, 2007

[42] S. S. Subhranshu, P. Jeyaraman and V. Vinita, "Sonochemical Coating of $\mathrm{Ag}-\mathrm{TiO}_{2}$ Nanoparticles on Textile Fabrics for Stain Repellency and Self-Cleaning-The Indian Scenario: A Review," Journal of Minerals \& Materials Characterization \& Engineering, Vol. 9, No. 6, 2010, pp. 519-525. 